\title{
Research on Human Resource Management for Telework Informati- zation under the Background of Epidemic Prevention
}

Jingting Lai*, Yangbin Wu

Nanning College for Vocational Technology, Nanning 530008, China. E-mail: jingtinglai@gmail.com

\begin{abstract}
The Corona Virus Disease in 2019 will have a serious impact on the normal operation of various industries. Under the environment of resuming work and production and ensuring safety, remote online office has become a core option for the operation of various industries. At present, remote office has met a lot of troubles, such as information asymmetry, inefficiency, regulatory difficulties, communication barriers, weakened confidentiality, and so on. This article focuses on exploring the mechanism of human resource management in remote office informatization in the context of epidemic prevention and control, and proposes distance education innovation for employee training, big data transformation, performance evaluation, and cloud computing. This article also focuses on solving the problems existed in the remote office. It suggests some useful and innovative human resource management paths. For example, improving data sharing, network optimization and remote collaborative office and others, all of them offer a good idea which provides human resource decision-making reference for the orderly resumption of work and production in various industries.
\end{abstract}

Keywords: Epidemic Prevention and Control; Remote Office; Informatization; Human Resource Management

\section{Introduction}

According to the announcement of the World Health Organization, the Corona Virus Disease has spread to many countries and regions around the world, and a global public health event has quickly formed. The International Labor Organization pointed out that the Corona Virus Disease affects 1.6 billion livelihoods worldwide, and more than 436 million companies face business risks. The global spread of the epidemic has had a huge impact on the resumption of work and production. China, Europe and other parts of the world have set off a wave of remote collaborative office under the premise of preventing and controlling the epidemic.

In China, thanks to the rapid development of e-commerce and logistics networks over the years, during the epidemic, various industries have turned to remote office, using virtual networks, virtual meetings, cloud technology, collaborative office software tools, etc. to achieve big data cloud collaboration. In addition to avoiding crowd focus and preventing infection, home office also saves human resource management costs. It not only ensures the continuity of business in various industries during the epidemic, but also makes online office in various industries more agile ${ }^{[1]}$. However, remote office is convenient. At the same time, it also brings unprecedented challenges. At present, remote office mainly has prominent problems such as information asymmetry, inefficiency, supervision difficulties, communication barriers, and weakened confidentiality. To a certain extent, this has caused new challenges to human resource management. Further research is urgently needed to solve the impact of remote working on human resource management.

Copyright (C) 2021 Jingting Lai et al.

doi: 10.18686/mmf.v5i1.2783

This is an open-access article distributed under the terms of the Creative Commons Attribution Non-Commercial License

(http://creativecommons.org/licenses/by-nc/4.0/), which permits unrestricted non-commercial use, distribution, and reproduction in any medium, provided the original work is properly cited. 


\section{The impact and enlightenment of the Corona Virus Disease on telecom- muting}

(1) Remote office informatization is imperative. The Corona Virus Disease is still continuing, and remote online office is an important component of the future plan of enterprises. For companies that urgently need to restore normal work order, remote collaborative office has become the life-saving straw for them. Due to the huge difference in personnel arrivals, companies are facing complicated employment management and other situations. Many companies are adjusting their resumption plans, and remote office is the best choice for non-contact office resumption during the epidemic. According to data, many companies across the country chose to allow employees to work remotely from home, and the scale reached 200 million ${ }^{[2]}$. Today, when information technology has been deeply integrated into people's work and life, remote work is becoming more and more frequent in daily life.

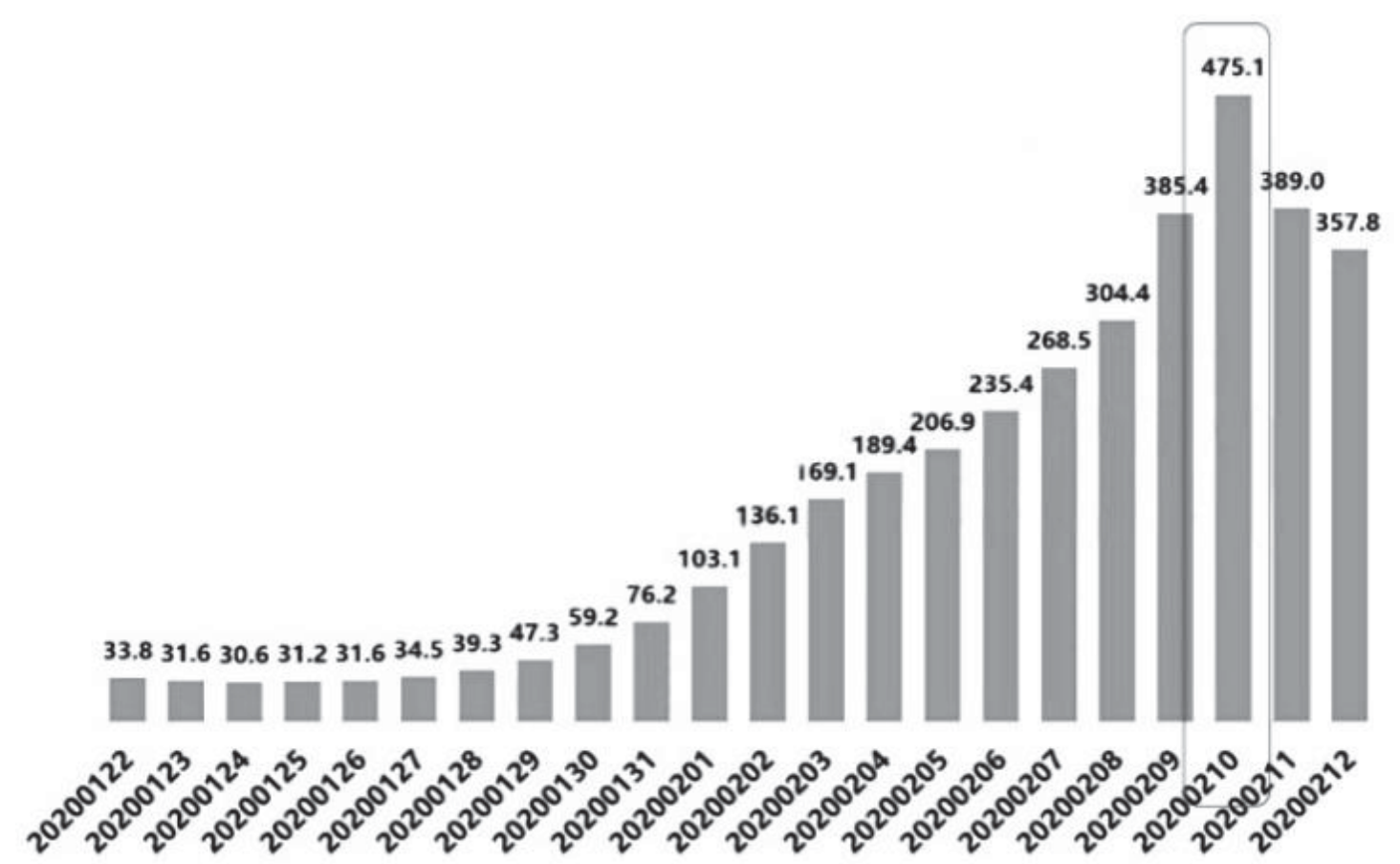

Figure 1. The daily increase trend of remote office users during the epidemic (unit: 10,000 people).

(2) Telecommuting presents new features and advantages. Telecommuting has very high flexibility, reducing the difficulties that physical distance brings to work, and allowing employees to complete work regardless of location and time. It reflects flexible labor and reduction cost, and increases the convenience of employees and other highlights. In the case of different places at the same time, using remote office tools to create the time synchronization and spatial distance of remote office can ensure that all kinds of meetings and work are carried out at the same time and let employees go to work in time. Except this, it also help make up for the loss of start-up and ensure the efficiency of remote collaboration. Remote online office is an important guarantee for the normal operation of the enterprise ${ }^{[3]}$. Remote online office can optimize the internal process of the organization, increase job refinement through online collaboration, and improve the organization and operation efficiency of the enterprise. Remote online Office can enable enterprises to realize virtual team management, and make online data quantifiable, traceable, and real-time management. Video conferencing is one of the most important functions of remote office, which can improve the efficiency of remote communication and virtual management. On the basis of referring to the company's management process and system, with the help of remoting, corporate managers can re-improve the company's organizational capabilities and the online assessment can be changed.

(3) There are prominent challenges and problems faced by remote office, such as information asymmetry, low efficiency, regulatory difficulties, communication barriers, and weakened confidentiality. In this epidemic, many employ- 
ees do not have remote office awareness, and a lot of companies also do not provide remote office hardware support. If re-mote technology is not in place, it will affect the realization of remote online office. Therefore, companies must prepare plans for remote office ${ }^{[4]}$. For remote office work at home, the company must confirm the identity of the employee to ensure the security of enterprise core servers.

\section{Analysis of the domestic status quo of telecommuting under the Corona Virus Disease}

On February 26, 2020, Mob Research Institute released the "Remote Office Industry Insights under the 2020 Epidemic", which provides important reference value for the future development direction of the remote office industry. Huawei Cloud Wwlink, Feishu, Graphite, Xiaoyuyi Lian and Di Shu jointly participated in the joint release of this report $^{[5]}$. The penetration rate of remote office in China is not very high, but it is growing rapidly, and there is still a lot of room for penetration in the future. Relevant data predicts that in 2020, China's remote mobile office industry market will enlarge. The scale will reach about 36.8 billion yuan ${ }^{[6]}$. By 2024, the Chinese market will reach 60 billion yuan. At present, China's remote office development still has a lot of room for development compared with western countries such as the United States. First, the supporting technology of remote office is becoming more mature. The popularization and development underlying 5G technology and cloud computing have greatly promoted the change of demand-level products in the remote office industry. At the application level, more and more Internet and technology giants are in the remote office market to promote industry's updates and development.

The short-term epidemic has catalyzed a surge in demand for remote office work. During the resumption of work after February 2020, more than 400 million users in China used remote office applications, and the number of new users is still increasing per day, which has already had users with a maximum of 4 million on February $10^{[7]}$. To seize market share as soon as possible, they are all competing to open up remote office resources for free.

Internet giants have moved to the Business-end market, and remote office has become a new point of contention. At present, DingTalk has the first-mover advantage in various indicators, and currently ranks first on the mobile side; followed by corporate WeChat. Because there has a large number of Customer-end users of Tencent, so it performs well. Feishu and WeLink are rising stars ${ }^{[8]}$. And the scale of daily activity is growing rapidly.

Audio and video conferencing software has harvested a number of white-collar users from first-tier and new first-tier cities. With a large number of middle-aged senior white-collar users, the platform has grown rapidly; the document collaboration platform has been steadily developing, and it has acquired a group of young users who love technology and the currency circle. During the epidemic, the mainstream remote office platform has launched basic medical-related functions such as health statistics and epidemic prevention guidelines. In the future, remote office companies will deepen cooperation with hospitals, and inject vitality into the online and intelligent level of the medical industry. The comprehensive type represented by DingTalk. During the epidemic, its remote office platform has been widely used in the online education industry. With the end of the epidemic, whether the active retention rate can continue to maintain a high level remains to be further tested by the market, but remote technology service companies will actually benefit from it. After the "window period" brought by the epidemic, user's demand has fallen, and there is a risk of user loss. But in the long run, with the rise of individual value, changes in employment relationships, and enhanced cross-regional cooperation, remote office will become a trend in the future.

\section{The impact of remote office informatization on human resource man- agement}

More than $80 \%$ of the interviewees believe that the biggest challenge at the moment is how to ensure the efficiency of employees in the remote office mode. More than $50 \%$ of the interviewed companies also believe that it has become a big challenge in achieving positively communicate policies, and easing employee emotions because of the lack of practical guidance for HR work, and it has difficulty in predicting the focus and adjustment of future work. For many HRs and enterprises, the remote office model is a fresh attempt. Employees are not in sight. How to control the work 
efficiency of employees is not only a challenge to HR, but also a major test for managers. For HR, the most important thing is to do a good job of guiding and formulating rules and policies.

(1) The impact on performance management. In addition, we found that in the employee office mode, whether managers can fully apply the employee's driving force factors to do a good job in the management and control of the remote office mode, which also has significant impact on the work efficiency of employees. Through data tracking and mining, Beizhi Talent Research Institute found that employees who value independent, flexible office and working atmosphere, wherever they work remotely or enter the workplace, the changes in the office environment will not affect their work efficiency ${ }^{[9]}$. On the contrary, employees who tend to face customers, interpersonal interaction, and growth opportunities, they will ask more attention from managers. They can quantify their work tasks, logs, morning and evening meetings and other management mechanisms to improve work efficiency.

(2) The impact on training. After the epidemic, $71 \%$ of companies will adjust their internal training methods and increase online training courses. In addition to recruitment, offline training will also be affected in a certain degree. Because crowds are afraid of infection, at least in the next 2-3 months, companies will no longer be able to organize offline training, and various training plans and arrangements made before the year will be forced to be suspended or postponed. Under such circumstances, the training work cannot be completely finished. If it is stagnant, companies must consider adjusting training methods and adding online training courses. It is worth noting that 54\% of companies will introduce emotional management, crisis management, and mental health courses into their training courses.

(3) The impact on recruitment. Companies that have insufficient talent echelon construction in normal times will face the great risks because the lack of personnel in key positions and the influence on underemployment. On the one hand, the current level of activity in the entire labor market is somewhat different. Reduction, coupled with limited recruitment forms, many companies and factories cannot recruit people. On the other hand, how to ensure the accuracy of the selection of candidates in video interviews and how to ensure the safety of new employees and other issues need to be resolved. Most companies will solve the problem of the accuracy of selection through talent evaluation. First they should find the right person, and then add the personnel as soon as possible through the entry medical examination such as nucleic acid testing, or choose to work at home and delay the entry as soon as possible. After research, it was found that only $22 \%$ companies will consider personnel adjustments, including job transfers, layoffs, and increasing outsourcing services. There are also a number of companies that will generate new recruitment needs due to the adjustment of their business.

More than $90 \%$ of the respondents believe that normal human resources work such as recruitment, performance, employee training and development will be affected by the epidemic. The epidemic has the greatest impact on human resource management in recruitment, accounting for the highest proportion, nearly $60 \%$, followed by the performance management, employee training and development, and human resource strategic planning, while it has the least impact on compensation and benefits and information systems.

\section{Human resource management path strategies under remote office during the epidemic}

(1) Actively implement safe rework and establish an emergency support team for rework during the epidemic. No matter when, no matter any implementation, we must ensure that the organization first. The enterprise shall set up a special emergency response team, clarify the responsibilities of its members and ensure their implementation. The support team should be led at least HRD (Human Resources Director) or higher Positions, who can unify the coordination of company resources, formulate systems and response plans, and have administrative power. During the Corona Virus Disease, the production chain will be split into: safe return to work, safe on-job, and safe outreach. First, safe return to work. We must first understand the health and mobility of employees. At the same time, according to the return time and self-isolation time limit, determine the personnel plan that can resume work to provide manpower protection for the next on-the-job production. Second, safe on the job. There are two levels of safety at work, the company's work area and the isolation area. The company concentrates on the work within the company's safety area, but for employees, the 
public area outside the company is still a polluted area, so the isolation area will be the most important work safety protection area. Third, safe outreach. Visits and outbounds should be both concerned. The company's visitors should make detailed records. For business trips, you need to fill in a form to file an application. No matter whether there is a city with a high epidemic situation in the destination and route of the trip or not, the company can make the approval conditions by itself.

(2) Actively explore training methods under remote office conditions. The first is to improve the professional skills and quality of employees. Although employees do not work in the office during the epidemic, they still need training and improvement. Taking into account the particularity of remote office, the time and location should be centralized. The traditional training method is obviously not applicable. Therefore, companies can use the Internet to effectively change the remote employee training plan and content, and transform the traditional face-to-face teaching model into a remote teaching model, so that employees can choose training flexibly and training efficiency. Distance education has now entered the $\mathrm{C} 2 \mathrm{C}$ era and is also an important part of remote office. Using the Internet, remote employees can share learning materials and exchange experience, which can not only improve the efficiency of employee training, but also promote communication and cooperation between employees. In order to create a good cultural learning environment for the company, distance education not only breaks the limitations of the traditional training model, but also enhances the loyalty of employees to the organization.

(3) Actively change the human resource performance appraisal method under big data. Human resource managers must have Internet thinking. Managers must learn to use the Internet and change traditional management thinking in order to effectively manage remote employees. When managing remote employees, they must transform performance appraisal from traditional time to output. What managers need to pay attention to is not only how long employees work, but how much work output employees complete and whether their work output can promote the development of the future enterprise. The use of output thinking is very important in remote office management, and the human resources department should set specific, quantifiable and realistic goals.

(4) Actively use big data management to evaluate remote employees in $360^{\circ}$. Human resources departments should use big data management in remote office to comprehensively evaluate the working status of remote employees in $360^{\circ}$ to promote production and operation. Big data technology integrates all data and manages. Through data analysis, they understand the work progress and work status of employees. The performance appraisal results are based on data, output-oriented, and are compatible with the remote employee evaluation system.

(5) Actively improve data sharing methods under cloud computing. The first is to establish a sense of sharing. There will be various resistances in remote office. Managers must fully realize that the information sharing platform is the prerequisite for managing remote office. The distance will be the lowest. The human resources department's big data management of employee information and the construction of an information sharing platform can stimulate the enthusiasm and creativity of employees. Employees share work progress in real time, making each employee's work content public, which is conducive to mutual supervision and the fairness of performance appraisal. The second is to establish an information sharing platform. The establishment of an information sharing platform can not only improve the work efficiency of employees, but also enhance employees' perception of the organization. Huang Zhangshu et al. proposed that the development and maturity of cloud computing technology are cross-cutting. The sharing of platform data resources has brought many benefits. Its powerful computing power, high storage, and low-cost characteristics make the sharing of resources more in line with actual needs. At the same time, it pays attention to cloud computing virtual technology for information storage and protects information security by improving encryption technology.

(6) Actively strengthen the self-defending network to optimize remote collaborative office. The first is to establish a safe and fast network system. Remote office is based on Internet technology. The frustration encountered by many remote office employees is mainly that they have encountered some network failures. And they have no technical solution, which reduces the efficiency of remote office, and at the same time increases the anxiety about remote office. If enterprises want to achieve the safe development of remote office, the establishment of a fast and stable network system is the foundation. The network information department is the enterprise's key departments must be on duty 24 hours a day to ensure that the network is unblocked. The second is to establish a remote office firewall. The information de- 
partment must build a security firewall for enterprise remote office to protect the transmission of remote files. Self-defending network is a new network architecture. It can quickly achieve a consistent security strategy and security configuration across the entire network, and make dynamic defense possible. Although self-defending network is still developing, it provides new ideas and means for the development of network security. Qi Zhonghou et al. proposed that with the help of solid information security system, in the Internet era, companies use the latest Internet technology to provide remote employees with training, incentives, assessment and sharing platforms to improve the efficiency of remote office and optimize the collaborative office system.

\section{Conclusion}

The Corona Virus Disease has brought many challenges to corporate human resource management. On the one hand, we must grasp the prevention and control of the epidemic, and at the same time, we must grasp the business operation and production. Most companies still put the safety of their employees in priority and choose remote office mode. Remote office can realize unbounded communication, flexible coordination and remote meetings. It is an important guarantee for the high-speed operation of enterprise organizations under the epidemic. The functions of remote office can enable employees to work in different places at the same time, and resume work and production more quickly. It will be an important component of the company's future plans. Human resource management should adapt to telecommuting in the Internet era. Companies should have big data thinking, and promptly transform the company's meeting, recruitment, training, and assessment systems, while paying attention to corporate information security issues to help resume work during the epidemic. Under the background of the using of remoting office, we should be ready to resume production at any time.

\section{References}

1. Wang R., Zhang S. Research on the challenges and opportunities of remote office management in the net background. Production and Operations Management 2018; (8): 87 - 92.

2. Zhou W. Precise efforts to provide all-round human resources guarantee for the resumption of work and production of enterprises. Nanjing Daily; 2020. p. 2.

3. Yang X. Dalian Municipal Party School, China Organized, during the epidemic prevention and control period, enterprises should organize the resumption of work and production in a scientific, safe and orderly manner. Dalian Daily; 2020. p. 6.

4. $\mathrm{Xu} \mathrm{W.} \mathrm{Ten} \mathrm{tips} \mathrm{on} \mathrm{labor} \mathrm{relations} \mathrm{risks} \mathrm{during} \mathrm{the} \mathrm{epidemic} \mathrm{period.} \mathrm{Rule} \mathrm{of} \mathrm{Law} \mathrm{Daily;} \mathrm{2020.} \mathrm{p.} 7$.

5. Fan J, Cai Z, Yang X, et al. Discussion on the management model of nursing human resources for new coronavirus infection pneumonia. Chinese Journal of Respiratory and Critical Care Medicine 2020. p. 134 - 136.

6. Liu Y. Business services in the post-epidemic era will usher in a new trend. Chinese Business; 2020 . p. 42 - 43.

7. Li C, Xie L. A number of cloud office companies are expected to see a surge in performance, and remote office welcomes the tens of billions of yuan market. Securities Daily; 2020. p. 2.

8. Ruo Y. Looking forward to telecommuting more efficient. China Labor and Social Security News; 2020. p. 8.

9. Li X, Shi D. Grab food! Is the turning point of telecommuting? School of Business 2020. p. 105-106. 